Thorax (1962), 17, 139.

\title{
THE MANAGEMENT OF RESPIRATORY DISTRESS AFTER CARDIOTHORACIC SURGERY
}

\author{
BY \\ ALAN GILSTON \\ From the Brompton Hospital, London
}

(RECEIVED FOR PUBliCATION JANUARY 12, 1962)

Lassen's employment of intermittent positive pressure respiration during the Copenhagen poliomyelitis epidemic (Lassen, 1953) has led to its use in a host of conditions, including post-operative respiratory complications. A number of authors have reported its value after cardiothoracic surgery (Björk and Engström, 1955, 1957 ; Björk, 1960 ; Buckley, Van Bergen, and Thiel, 1960 ; Spencer, Benson, Liu, and Bahnson, 1959), but discuss only a few of the problems involved. This paper describes in detail the management of respiratory distress after cardiothoracic surgery. It is based on a series of 50 cases.

\section{Material}

The majority of the patients were treated following surgical correction of heart disease, usually with the aid of cardiopulmonary bypass (Table I). Many were bad operative risks, either from the nature of their lesion or from pre-operative complications. All required respirator treatment for respiratory distress.

TABLE I

\section{RESPIRATOR TREATMENT AFTER CARDIOTHORACIC} SURGERY IN A SERIES OF 50 PATIENTS

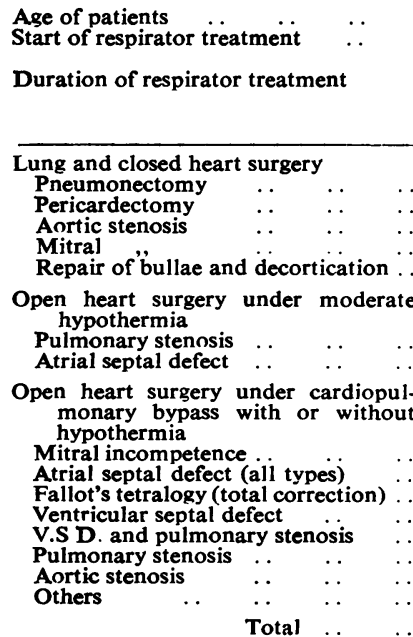
3-65 years Immediately -17 days after operation 4 hours -28 days

Cases Survivors

(1)

$\begin{array}{ll}3 & 2 \\ 2 & 0 \\ 2 & 1 \\ 2 & 0 \\ 1 & 1 \\ & \\ 1 & \\ 2 & 0\end{array}$

$\begin{array}{rr}7 & 2 \\ 7 & 4 \\ 6 & 2 \\ 5 & 4 \\ 3 & 1 \\ 3 & 2 \\ 4 & 1 \\ 2 & 0 \\ 50 & 20\end{array}$

\section{Method}

Tracheostomy was performed in all cases, usually under general anaesthesia, as this provided ideal operating conditions. In addition, some patients required immediate intubation and respirator treatment. High tracheostomy with a tracheal flap sutured to the skin (Björk, 1960) was preferred. This flap was not disturbed when the tube was eventually removed. When gastric dilatation or paralytic ileus was present, a Ryle's tube was passed.

Silver tracheostomy tubes were found most suitable, Negus tubes being appropriately modified (Gilston, 1961). Their advantages over rubber ones included ease of insertion with an introducer, an inner tube that could be removed and cleaned, a speaking tube, which increased the effectiveness of coughing when the patient was breathing spontaneously during weaning, and their short length, which made bronchial intubation unlikely. Björk (1960) had not seen tracheo-oesophageal fistulae with silver tubes. Their disadvantages included the occasional sliding out of the inner tube, their unsuitability for patients with a thick neck or a low tracheostomy, and the possibility of the components being mislaid. Each set was distinctly marked to prevent confusion. The smallest possible latex cuff was used in order to grip the tube firmly, and airway obstruction from a dislodged cuff was never seen.

For adults, sizes 34 to 28 were satisfactory, the larger sizes being best, as these offered a lower resistance to gas flow, were less likely to be blocked by secretions, and did not require excessive inflation of the cuff to produce an airtight fit. Young children did not necessarily require cuffed tubes, provided care was taken to avoid the inhalation of secretions and vomit when they were comatose or therapeutically paralysed. This allowed the use of a larger tube, made tracheal ulceration less likely, and occasionally permitted them to talk. A disadvantage was the consequent air leak, which prevented accurate measurement of ventilation or use of the rebreathing technique for estimating $\mathrm{paCO}_{2}$.

Intermittent positive pressure respiration was carried out with a Radcliffe positive or positivenegative respirator. These are time-cycled machines. the number of times a minute the patient is inflated being regulated by a motor with variable gears. 
independently of the tidal volume or inflation pressure. The tidal volume depends on the pressure created by a variable weight acting on a bellows. On the positive-negative machine another bellows creates a subatmospheric ("negative") pressure during expiration. A thermostatically controlled humidifier moistens the inspired gases.

Patients were connected to the respirator as follows: (1) The respirator was set and switched on ; and (2) the patient's breathing was then manually controlled before connecting him to the respirator.

(1) SETting THE RESPIRATOR.--The positive pressure was set at "maximum," approximately $35 \mathrm{~cm}$. of water, and was unlikely to damage even a child's lungs. It was adjusted once intermittent positivepressure respiration was established. The rate was set at 20 per minute. A negative pressure of minus 5 to $10 \mathrm{~cm}$. of water was occasionally used in hypotensive cases but was always avoided in emphysema for fear of air trapping.

An oxygen-rich mixture was used routinely in the early stages of treatment. Oxygen, 2 to 3 litres $/ \mathrm{min}$., was fed into the respirator, producing an oxygen concentration of at least $40 \%$. This helped to compensate for the arterial desaturation commonly present, especially after open heart surgery under cardiopulmonary bypass.

(2) Manual Control of Respiration.-Once a patient had recovered from the anaesthesia, direct connexion to the respirator was often found unsatisfactory, as he breathed or "fought" against the machine. This produced inadequate ventilation, a fall in cardiac output with hypotension, and in one case, already in advanced heart failure, cardiac arrest. Initial hyperventilation by hand facilitated controlled respiration, showed if other measures to stop fighting were required, and gave a clinical estimate of lung compliance and airway resistance.

The technique was as follows. An anaesthetic bag was filled with oxygen at a flow rate of 10 litres/ min. and connected to the tracheostomy tube. The patient was then manually hyperventilated, the tracheostomy cuff being inflated just sufficiently to provide an airtight seal. The high flow rate of oxygen prevented rebreathing, the excess escaping through an adjustable spring valve. At first the patient's breathing was merely augmented, but the inflation rate and tidal volume were gradually increased over several minutes until spontaneous respiration was virtually abolished. The respirator was then rapidly substituted. No ill effects were seen in these cases from the rapid fall in $\mathrm{paCO}_{2}$.

This measure was frequently impossible without simultaneously depressing the respiratory centre with a narcotic such as omnopon (papaveretum) gr. $\frac{1}{6}$ to $\frac{1}{3}$ (10 to $20 \mathrm{mg}$.) or pethidine 25 to $50 \mathrm{mg}$. intravenously. with a similar intramuscular dose to prolong the effect. Smaller doses in children were satisfactory. If this failed or if the patient was comatose or hypotensive. a small dose of tubocurarine, 3 to $5 \mathrm{mg}$.. was given intravenously. Paralysing doses were rarely required. This relaxant was chosen because of its long duration and lack of side-effects.

The initial aim was a tidal volume of 500 to $600 \mathrm{ml}$. in adults and about half this in small children. At an inflation rate of 20 per minute the minute volume was now 10 to 12 litres, usually sufficient to lower the paCO2 below $30 \mathrm{~mm}$. of mercury and prevent "fighting." In some patients, particularly those with extensive lung disease, the maximum pressure produced an inadequate tidal volume (less than $300 \mathrm{ml}$.) and a faster rate was also required. If this failed to produce adequate ventilation. the prognosis was bad.

Fighting was likely to occur at any time after intermittent positive pressure respiration had been established. It was common after tracheal aspiration, but the patient usually settled down quickly. Other stimuli, such as secretions in the tracheo-bronchial tree, pain. a full bladder, or anxiety, were sometimes responsible, and occasionally it was due to hypoventilation. It was often severe in the presence of brain damage, gross circulatory failure, or advanced lung disease. Very often no obvious cause was found. If fighting was marked, and particularly if sweating. tachycardia, and hypotension appeared. additional narcotic or tubocurarine was given and manual hyperventilation was again performed. When fighting occurred immediately after beginning respirator treatment. or persistently recurred afterwards without obvious cause, ventilation was increased regardless of its possible effect on the paCO. A faster rate was frequently more effective than a greater tidal volume and very often the pressure was already at maximum. A minor degree of fighting was not dangerous and was likely to disappear spontaneously. When it persisted, intramuscular narcotic or tubocurarine was usually effective. After the first day or two most conscious patients, including children, rarely required drugs for fighting. Mild sedation was often helpful in nervous cases, but chlorpromazine was never used for this purpose because of its side-effects and potential toxic effects. the barbiturates being preferred.

Frequently several hours elapsed after the beginning of respirator treatment before the $\mathrm{paCO}_{2}$ reached its minimum. When intermittent positive pressure respiration had been satisfactorily maintained for this period, ventilation was adjusted to produce a paCO. of 25 to $30 \mathrm{~mm}$. of mercury. The tidal volume required was generally 50 to $100 \%$ greater than that predicted by the Radford nomogram (Radford, Ferris, and Kriete. 1954). In some cases a lower $\mathrm{paCO}_{2}$ was initially required to prevent fighting, though in others it did not occur with a normal or even raised $\mathrm{paCO}_{2}$. As many patients improved, progressively less pressure was required to produce a given tidal volume.

The absence of fighting and other clinical evidence of hypoventilation did not exclude the presence of a raised $\mathrm{paCO}_{3}$. such a state being precarious. Changes in minute volume were often difficult to interpret, and 
although they sometimes signified a leak or obstruction in the respiratory pathway, more often there was no obvious cause.

Hyperventilation was used in preference to tubocurarine to abolish spontaneous respiration. It has been used with success in the management of crushed chest (Avery, Mörch, and Benson, 1956). In paralysing doses tubocurarine abolishes the cough and swallowing reflexes and makes assessment of the conscious state difficult. Hyperventilation diminishes the respiratory drive by lowering the $\mathrm{paCO}_{2}$ and stimulating the Hering-Breuer reflex. It does not interfere with protective reflexes; the patient can move normally, communicate, and in an emergency breathe spontaneously. It promotes the expansion of atelectatic lung and prevents its occurrence. It also provides a safety margin against minor changes in ventilation. A metabolic acidosis was frequently present after open heart surgery, and the loss of $\mathrm{CO}_{2}$ helped to compensate for this. The rarity of secondary pulmonary complications in these patients may have been due partly to their ability to cough.

The main disadvantages of hyperventilation are its failure to eliminate fighting completely and its effect on cerebral blood flow. Increasing cerebral vasoconstriction occurs as the $\mathrm{paCO}_{2}$ falls below normal, and there is strong evidence that this interferes with brain function, particularly when the $\mathrm{paCO}_{2}$ falls below $25 \mathrm{~mm}$. of mercury (Otis, Rahn, Epstein, and Fenn, 1946). Only one conscious patient showed signs of this. She was a middle-aged woman who became very drowsy during marked hyperventilation and woke up when it was reduced. Some patients with brain damage recovered consciousness after a variable period despite vigorous hyperventilation, but others died in coma. The safety of a low paCO in such cases remains uncertain, particularly when fits are occurring or when there is advanced circulatory failure.

Other reported disadvantages of hyperventilation in respirator cases were rarely a problem. Weaning off the respirator was usually accomplished without difficulty. There was little risk of renal calculi formation. Calculi take at least six weeks to develop in paralysed poliomyelitis patients (Plum, 1958), and the importance of respiratory alkalosis is uncertain as they also occur in paraplegia (O'Connell and Gardner, 1953). Tetany was seen once.

All patients had physiotherapy two or three times a day unless their circulatory state was extremely poor. It was also performed during spontaneous respiration after weaning was well established. The head-down position was temporarily abandoned in some cases because it was badly tolerated. Patients were initially nursed flat (with one or two pillows) and their position was changed two-hourly.

\section{RESULTS}

In most cases respirator treatment was started within the first two days after operation and lasted up to 28 days. The initial response varied, but there was usually some immediate improvement in the patient's condition and often this was dramatic, even in subsequently fatal cases.

Twenty out of 50 patients survived, a mortality of $60 \%$. Death was due to a variety of causes. Heart failure was the commonest following open heart surgery, respirator treatment merely abolishing one manifestation of its presence. Heart block, brain, lung, or liver damage, renal failure, haemorrhage, and surgical errors were other or contributory causes. In the patients who had lung or closed heart operations, death was due to heart failure, advanced lung disease, or brain damage.

The survivors did not all make a full recovery. Only one patient, an elderly man who had had a pneumonectomy for carcinoma, remained a respiratory cripple, but several were left with a residual hemiplegia or intellectual impairment, a reopened septal defect or heart block.

\section{Discussion}

The main advantages of respirator treatment are the establishment of adequate pulmonary ventilation and the abolition of respiratory work, which in respiratory distress may be considerably raised. Intermittent positive pressure respiration also stops paradoxical breathing and is often more effective than oxygen therapy alone in relieving anoxaemia. In addition, adequate doses of narcotic analgesics can be given without regard to their respiratory depressant effect. The main disadvantage of intermittent positive pressure respiration is the need for special facilities. Patients require constant skilled nursing in a special ward. The value of intermittent positive pressure respiration in the treatment of respiratory distress justifies its use, and nurses quickly learned the techniques involved in the management of these cases.

The term " respiratory distress" is preferable to either " respiratory failure" or " respiratory insufficiency" when discussing these cases. Purely clinical, it signifies that breathing is abnormal without reference to either the cause or the blood gas state. The other terms commonly imply a raised partial pressure of carbon dioxide in the arterial blood and/or a diminished arterial oxygen saturation, and are misleading, as a respirator may be required to ease the respiratory burden before such changes occur.

Many factors before, during, and after operation can lead to post-operative respiratory distress. They act either by diminishing the patient's respiratory power or by increasing the respiratory 
work. In either event the ventilatory requirements may be normal or raised. The cause may lie particularly in the respiratory, cardiovascular, or central nervous systems, each of which affects the others. Untreated, respiratory distress leads to a vicious circle of exhaustion, increasing respiratory failure, falling cardiac output, and coma (Fig. 1).

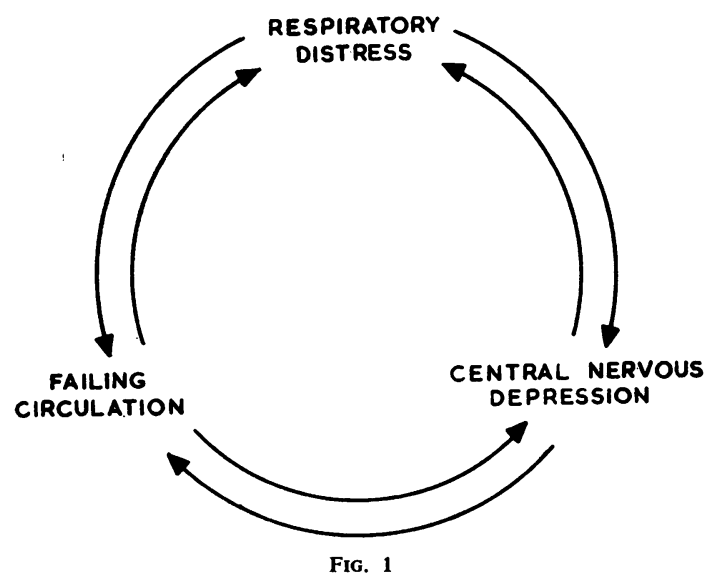

In these patients respiratory distress after open heart surgery was mainly attributed to heart failure. Often no obvious cause was found, but other or contributory factors included the ill effects of thoracotomy and cardiopulmonary bypass on the lungs, metabolic acidosis, and damage to the central nervous system. In the other cases heart failure or pulmonary complications were chiefly responsible. Clinical evidence was much more valuable than investigations in deciding when to use a respirator. The degree of respiratory distress in these patients varied considerably. With the exception of severe dyspnoea or gross hypoventilation, no single sign made immediate respirator treatment imperative, but it was used when there was obvious or increasing respiratory distress, or mild respiratory distress with either a failing circulation or central nervous depression. Greater experience led to earlier employment of respirator treatment following open heart surgery under cardiopulmonary bypass, to avoid the risk of further deterioration.

Dyspnoea was the paramount symptom of respiratory distress. It was accompanied by a number of signs of which activity of the alae nasi was one of the earliest and most valuable, and a respirator was usually required when this was marked and sometimes when it was only slight. Sweating generally signified increased respiratory effort. Mouth breathing was a bad sign when it persisted despite tracheostomy. There was often accessory muscle activity and occasionally an inspiratory tracheal tug. Cyanosis was a sign of doubtful value. The difficulty of detecting and interpreting it and its grave significance when it was due to inadequate breathing were recognized, and it was not awaited before using a respirator, particularly if the patient was already having extra oxygen.

Tachypnoea was common, and the respiratory rate occasionally rose to 40 per minute in adults and even higher in young children. Unless the rate was rising, it did not necessarily mean intermittent positive pressure respiration was required. Bradypnoea was rare. Though CheyneStokes respiration lowers the $\mathrm{paCO}_{2}$, it was regarded as an additional but not sole indication for respirator treatment. Paradoxical respiration was frequently present after bilateral thoracotomy with transverse sternotomy, and Gerbode, Braimbridge, and Melrose (1958) have criticized this incision. Restlessness, jerky and laboured breathing, and active expiration were further signs of respiratory distress.

Neither clinical assessment of ventilation nor its accurate measurement with an anemometer were reliable guides to blood gas state, though an adult with a tidal volume of less than $200 \mathrm{ml}$. certainly required a respirator. Apparently normal or increased ventilation was frequently associated with a raised $\mathrm{paCO}_{2}$.

A low or falling blood pressure was common in these patients and had a variety of causes. Some, in a low output state, maintained a satisfactory blood pressure by intense peripheral vasoconstriction. Their extremities became cold and cyanosed. A rising blood pressure from carbon dioxide retention was rarely seen. The pulse was not a reliable guide to the need for intermittent positive pressure respiration as it was frequently unaffected by increasing respiratory distress.

Some patients did not regain consciousness after operation, others became progressively drowsy. There were a number of causes, including brain damage, advanced circulatory failure, and respiratory failure.

Chest radiographs excluded obvious causes of respiratory distress. They were no guide to the need for respirator treatment, though when abnormal they were valuable in assessing progress. Arterial gas and $p \mathrm{H}$ investigations were not essential and were not always performed, but they provided useful information in doubtful cases. The rebreathing technique of estimating $\mathrm{paCO}_{2}$ (Campbell and Howell, 1960) was often compared 
with simultaneous arterial samples, and proved reasonably accurate, the $\mathrm{pCO}_{2}$ difference usually being 5 to $10 \mathrm{~mm}$. mercury. It was unreliable in patients with a very low cardiac output after open heart surgery.

A raised $\mathrm{paCO}_{2}$ is common for the first 48 hours after thoracotomy, the time when respirator treatment was usually started, and a $\mathrm{paCO}_{2}$ of $60 \mathrm{~mm}$. mercury was often seen in patients who were not suffering from chronic lung disease and who were otherwise making satisfactory clinical progress. The $\mathrm{paCO}_{2}$ in patients who required respirator treatment was frequently lower than this and occasionally was normal or below. Thus for the first 48 hours after thoracotomy the $\mathrm{paCO}_{2}$ was little guide in deciding whether to use a respirator, unless it was rising or had reached the dangerous level of $70 \mathrm{~mm}$. mercury. Arterial oxygen desaturation which responded poorly to oxygen therapy was an additional indication for intermittent positive pressure respiration, as was a metabolic acidosis which persisted despite the administration of sodium bicarbonate.

Once intermittent positive pressure respiration was established, arterial puncture was performed only when there was technical difficulty with the rebreathing technique or uncertainty about the blood gas and acid-base state. The urine remained acid ( $p \mathrm{H} 3$ to 6) despite the persistent respiratory alkalosis and was no guide to the $\mathrm{paCO}_{2}$. In most cases daily estimation of the $\mathrm{paCO}_{2}$ with the rebreathing technique was adequate.

In doubtful cases tracheostomy was carried out. Apart from its well recognized advantages of decreasing dead space and airway resistance and providing access to retained secretions it enabled controlled respiration to be carried out immediately it became necessary, often directly after tracheostomy. The patient was then closely observed. In the great majority of patients in whom a tracheostomy was performed for respiratory distress after open heart surgery, it appeared to be of little benefit and respirator treatment was required within a few hours.

Hypotension was also frequent and occurred both before and after the start of respirator treatment. It had a variety of causes including heart failure, low output states, arrhythmias, haemorrhage, and respiratory failure. Intermittent positive pressure respiration can produce hypotension when the blood volume is low (Mushin, Rendell-Baker, and Thompson, 1959), but this occurred in only one of our patients, who was dehydrated and responded to intravenous fluids. When the blood pressure was already falling from advanced heart failure before respirator treatment was started, the part played by intermittent positive pressure respiration in a continued fall was difficult to assess. Improvement in the blood pressure often followed the use of a respirator. A negative phase rarely had any beneficial effect and no conclusions were drawn about its value. The efficacy of sustained positive pressure during pulmonary oedema was also uncertain. When other measures failed, vasopressors, particularly Aramine (metaraminol bitartrate), were used to correct hypotension. It was given as a slow intravenous infusion, in some cases for about a week. A poor response in one patient was found to be due to undiagnosed adrenal haemorrhage and this was a contributory factor in another. In some cases correction of a metabolic acidosis improved the response.

Ileus was common. Though reported in many conditions treated with intermittent positive pressure respiration, it probably has no special respiratory significance as it frequently occurs following trauma of any kind and in gravely ill patients. Varying in severity, it was present before or after the beginning of respirator treatment and usually disappeared in two or three days. The routine use of hyperventilation was possibly beneficial, as it increases gastric motility (Danielopolu and Savulesco, 1928). Constipation was occasionally troublesome in the early stages of treatment, the abdomen becoming distended with unexpelled gas. The narcotics did not appear to be responsible. Treatment with a flatus tube and a suppository was usually effective.

Another complication was convulsions. These were usually the result of brain damage or acute circulatory failure, and they sometimes required paralysing doses of curare to control them. This treatment was also occasionally required for extreme restlessness. In a few cases convulsions were due to anoxia produced by prolonged tracheal suction or to fighting the respirator during the terminal stages of advanced lung disease.

Humidification did not prevent partial obstruction of the tracheostomy tube with blood clot or secretions. The inner tube was therefore removed and cleaned daily. The cuff was deflated for two minutes every hour, though there is no evidence that this prevents tracheal ulceration. The trachea was aspirated hourly with an angled whistle-tipped catheter and 5 to $6 \mathrm{ml}$. of saline squirted down the tracheostomy tube when the sputum was very tenacious. The tracheostomy wound healed more satisfactorily without dressings, provided it was kept clean and sprayed with Polybactrin four- 
hourly. The tracheostomy tube was changed only occasionally, about once a fortnight, or if the cuff burst, a rare event. Mechanical breakdown of the respirator was rare. Constant vigilance by the nurses ensured that disconnexion from the respirator and similar accidents were never fatal. Respirator readings were taken hourly.

A number of signs were found to carry a bad prognosis if they persisted during intermittent positive pressure respiration. These included the need for paralysing doses of tubocurarine to stop fighting; failure of the respirator to provide adequate ventilation; continuous and marked activity of the alae nasi; progressive diminution in consciousness; a falling blood pressure despite increasing doses of vasopressors; and widely dilated pupils in the presence of a failing circulation, whether or not the patient was conscious.

Weaning off the respirator was not started until certain criteria were satisfied, the decision being based almost entirely on clinical evidence. Measurement of vital capacity or ventilation was found to be of little value in making a decision. The most important index was the patient's general condition, which was nearly always good. He was conscious and rational and had started to eat. His oral temperature was not more than $100.5^{\circ} \mathrm{F}$. The lungs were clear both clinically and radiologically, with little or no paradox on spontaneous respiration. There was no cyanosis of respiratory origin on air alone. The blood pressure was satisfactorily maintained without vasopressors and the pulse rate kept at not more than 120, with an arrhythmia, if present, under control. Other evidence of heart failure did not preclude weaning. The haemoglobin was at least $85 \%$ and the serum potassium normal. Several cases required blood transfusion immediately before weaning was started. Occasionally weaning had to be commenced without all these criteria being satisfied.

A pCO ${ }_{2}$ of 35 to $40 \mathrm{~mm}$. $\mathrm{Hg}$ during intermittent positive pressure respiration appeared to facilitate weaning. This was often achieved without producing fighting, particularly if the adjustments were made whilst the patient was asleep. If fighting occurred, the attempt was temporarily abandoned. The tidal volume, and the rate if over 20, were gradually reduced 24 to 48 hours before weaning was commenced. The Radford nomogram was not always a reliable guide, giving too low an estimate in some cases.

It was rarely possible to start weaning before the third day of respirator treatment, and occasionally it was several weeks before the patient was ready. Once it was well established, progress was usually rapid, but if a relapse occurred the procedure was temporarily abandoned. Initially hyperventilation was common, but the $\mathrm{paCO}_{2}$ gradually returned to normal except in two patients (both of whom had had a pneumonectomy) in whom it was higher. Respiratory stimulants were tried on several occasions and found to be of little value.

The technique was to disconnect the respirator and slowly and gently inflate the patient by hand. Once breathing began, either spontaneously or after command, the cuff was deflated and humidified oxygen was delivered by a tracheostomy T-piece (Gilston, 1961). A speaking tube was inserted during the later stages of weaning unless the tracheostomy tube was a close fit. Weaning was left to the nurses after the first few attempts had been satisfactory.

A limit was set to the periods off the respirator during the early stages of weaning, and these were often as little as a minute or two every hour. When they had reached about 30 minutes per hour, the patient largely decided their length. Clinical signs were the best guide, and the nurse reconnected the respirator if any of the following signs appeared before the weaning period expired. They were listed on a chart by the bedside: (1) The patient asks to be reconnected, is tired or restless, or if there is any doubt; (2) there is obvious dyspnoea (here the patient's opinion is most important), marked activity of the alae nasi, or the respiratory rate rises by more than 10 above its initial value; (3) there is marked sweating, the hands become cold and clammy, or facial pallor or cyanosis appears ; (4) the blood pressure falls by more than $10 \mathrm{~mm}$. $\mathrm{Hg}$ or the pulse rate rises by more than 10 (alterations in the opposite direction should be ignored). If marked fighting occurred when the respirator was reconnected at the end of the weaning period, the machine was discontinued for a little longer if this was well tolerated. Otherwise manual ventilation was performed, narcotics and relaxants being avoided whenever possible.

When the patient had been off the respirator throughout the day, he was taken off at night. This was often successful at the first attempt and the patient ceased to require the respirator. The duration of weaning varied considerably and bore little relationship to the previous duration of intermittent positive pressure respiration. The first few days were frequently very discouraging, but few patients developed an emotional 
dependence on the respirator and most were very willing to abandon it. This rarely took more than a week, and one patient dispensed with the machine at his first attempt. Once weaning was complete, it was permanent. The tracheostomy tube was removed when tracheal aspiration was no longer necessary, generally two to three days later. Corking was not required.

\section{SUMMARY}

The aetiology and treatment of respiratory distress occurring in 50 patients after cardiothoracic surgery are described. Despite a mortality of $60 \%$, intermittent positive pressure respiration was considered to have been beneficial.

The indications for using a respirator, the techniques involved, and the possible complications are discussed. The importance of clinical signs is emphasized.

In this series hyperventilation was used in preference to curarization as the method of controlling respiration.

I am indebted to the consultant surgeons of the Brompton Hospital for permission to publish details of their cases. I would also like to thank the many consultants, colleagues, and other members of the staff who have offered me advice and criticisms. The management of these cases was shared with my anaesthetist colleagues, Dr. J. R. E. Jenkins and Dr. Wendy Clark.

\section{REFERENCES}

Avery, E. E., Mörch, E. T., and Benson, D. W. (1956). J. thorac. Surg., 32, 291.

Bịörk, V. O. (1960). Ibid., 39, 179.

— and Engström, C. G. (1955). Ibid., 30, 356

- - (1957). Ibid., 34, 228.

Buckley, J. J., Van Bergen, F. H., and Thiel, N. A. (1960). Anesth. - Analg. Curr. Res., 39, 121.

Campbell, E. J. M., and Howell, J. B. L. (1960). Brit. med. J., 1, 458.

Danielopolu, D., and Savulesco, A. (1928). J. Physiol. Path. gen., 26, 225.

Gerbode, F., Braimbridge, M. V., and Melrose, D. G. (1958). A.M.A. Arch. Surg., 76, 821.

Gilston, A. (1961). Lancet, 1, 1326.

Lassen, H. C. A. (1953). Ibid., 1, 37.

Mushin, W. W., Rendell-Baker, L., and Thompson, P. W. (1959) Automatic Ventilation of the Lungs, Ch. 1. Blackwell, Oxford.

O'Connell, F. B., and Gardner, W. J. (1953). J. Amer. med. Ass., $153,706$.

Otis, A. B., Rahn, H., Epstein, M. A., and Fenn, W. O. (1946). Amer. J. Physiol., 146, 207.

Plum, F. (1958). J. Amer. med. Ass., 168, 1302.

Radford, E. P., Ferris, B. G., and Kriete, B. C. (1954). New Engl. J. Med., 251, 877.

Spencer, F. C., Benson, D. W., Liu, W. C., and Bahnson, H. T. (1959). J. thorac. Surg., 38, 758. 